\title{
Structural characterisation, citral retention and thermal properties of the inclusion complex of rice starch-lemongrass extract
}

\author{
${ }^{1}$ Hashim, M.A., ${ }^{1 *}$ Yahya, F., ${ }^{1}$ Hamzah, Y., ${ }^{2}$ Wan Aida, W.M. and ${ }^{3}$ Khalid, K.H. \\ ${ }^{1}$ Faculty of Fisheries and Food Science, Universiti Malaysia Terengganu, 21030 Kuala Nerus, Terengganu, \\ Malaysia \\ ${ }^{2}$ School of Chemical Sciences and Food Technology, Faculty of Science and Technology, Universiti \\ Kebangsaan Malaysia, 43600, Bangi, Selangor, Malaysia \\ ${ }^{3}$ Food Science and Technology Research Centre, Malaysia Agriculture Research and Development Institute \\ (MARDI), Persiaran MARDI-UPM, 43400 Serdang, Selangor, Malaysia
}

\author{
Article history: \\ Received: 7 November 2019 \\ Received in revised form: 14 \\ January 2020 \\ Accepted: 15 January 2020 \\ Available Online: 18 \\ February 2020
}

\section{Keywords:}

Lemongrass extract,

Citral retention,

Inclusion complex,

Rice starch,

Morphological structures,

Thermal properties

DOI:

https://doi.org/10.26656/fr.2017.4(3).367

\begin{abstract}
The citral compound that contributes to the strong-lemony odour of lemongrass has high volatility and low physicochemical stability. To overcome the problems, the inclusion complex of the encapsulation technique was applied with rice starch as a coating material to improve the stability and protect against any unfavourable reaction. Therefore, this study was conducted to determine the structural characterization, citral retention and thermal properties of native rice starch, gelatinised rice starch, inclusion complex of rice starch-citral compound, and inclusion complex of rice starch-lemongrass extract. Lemongrass extract and standard citral compound were homogenised into rice starch dispersion at $80^{\circ} \mathrm{C}$ for $15 \mathrm{mins}$ and freeze-dried at $-50.0 \pm 2.0^{\circ} \mathrm{C}$. The formation of the inclusion complex powder was determined using different analyses including morphological structure using the scanning electron microscope, crystallinity structure was determined with X-ray diffractometer, identification and quantification of citral compound using HS-SPME-GC-FID and the thermal properties of inclusion complex analyzed using differential scanning calorimetry. The microstructure of both inclusion complex of rice starch-lemongrass extract and rice starch-citral compound exhibited a laminated multiangular shape with crumble formation together with the characteristics of V-type pattern of crystalline complexes. The low degree of crystallinity of the inclusion complex of rice starch-lemongrass extract obtained high in citral entrapment $(29.34 \pm 3.13 \%)$ with the highest concentration of citral retention $(7.33 \pm 0.78 \mathrm{ppm})$. Both inclusion complex of rice starch-citral compound and rice starch-lemongrass extract displayed an endothermic peak at $138^{\circ} \mathrm{C}$, which is attributed to an inclusion complex occurrence with significant difference $(p<0.05)$ of enthalpy of $0.44 \pm 0.05 \mathrm{~J} / \mathrm{g}$ and $1.61 \pm 0.70 \mathrm{~J} / \mathrm{g}$, respectively. These findings showed that rice starch was effective in complexing with aroma compounds in improving the stability and protecting the citral compound of lemongrass extract from any unwanted changes. This inclusion complex should be regarded as an important strategy in designing a novel model of citral compound of lemongrass for food flavouring application.
\end{abstract}

\section{Introduction}

Lemongrass (Cymbopogon citratus) is a well-known aromatic herb that is widely cultivated in tropical and subtropical climates in Indochina, Indonesia, Malaysia, Sri Lanka as well as Northern and Southern of India (Francisco et al., 2011). It is commercially used in pharmaceutical (Shah et al., 2011), cosmetic (Mohamed Hanaa et al., 2012), and food flavouring (Katsukawa et al., 2010) industries due to its strong lemony odour contributed by the geometric citral isomers of neral and geranial (Weisheimer et al., 2010) that makeup to 65$80 \%$ of the total volatile composition (Carlson et al., 2001; Schaneberg and Khan, 2002; Nakahara et al., 2003). Nevertheless, the instability and volatility of citral compound are inconveniences causing a short flavour lifespan (Vaughn et al., 2009; Xiao et al., 2015) that is linked to oxidation and volatilisation (Ruktanonchai et al., 2011). 
The adverse effect on the citral compound of lemongrass can be overcome using encapsulation process through the inclusion complex technique (Cohen et al., 2008; Putseys et al., 2010) by entrapping the aroma compound within starch polymer chains in heterogeneous or homogenous matrices (Wang, Yang and Yue, 2015). This application is to secure the susceptibility of the citral compound by protecting it from any unfavourable changes (Nazarro et al., 2012; Yahya et al., 2016). Starch is a suitable material in the preparation of inclusion complex and act as encapsulating guest molecules that fulfil the selection criteria including bland taste, inertness, and economic viability (Gharsallaoui et al., 2007; Nazarro et al., 2012) such as $\beta$-cyclodextrin (Wang et al., 2011), tapioca starch (Itthisoponkul et al., 2007), corn starch (Cohen et al., 2008; Zhang et al., 2013), and rice starch (Keatkrai et al., 2017).

Starch consists of amylose and amylopectin chains that bind with aroma compounds or guest molecules. Amylose chains interact with the hydrophobic part of guest molecules on their helical cavity in structuring the inclusion complex (Conde-Petit et al., 2006; Itthisoponkul et al., 2007; Zhang et al., 2013), whereas amylopectin chains form a network structure between guest molecules (Conde-Petit et al., 2006) under an aqueous solution (Wulff et al., 2005). Amylose was reported to form helicoidally inclusion with small molecules like iodine, emulsifiers, lipid, and flavour compound (Arvisenet and Cayot, 2001) while amylopectin has a weak ability to form inclusion complexes with hydrocarbon compounds (Arvisenet et al., 2002). The presence of water is to augment the polar interaction of the hydrogen bonds between the hydroxyl groups of starch and volatile compounds (Van Ruth and King, 2003) during the inclusion complex formation. Weak chemical forces like van der Waals forces, dipoledipole interactions, and hydrogen bonding are involved in the entrapment of volatile compounds with the helical structure of starch (Gupta et al., 2016). Therefore, the study aimed to characterize the morphology, crystallinity structure and thermal properties of native rice starch, gelatinised rice starch, inclusion complex of rice starchcitral compound, and inclusion complex of rice starchlemongrass extract as well as to determine the retention concentration and entrapment efficiency of citral compound from different types of inclusion complex powders.

\section{Materials and methods}

Fresh lemongrass stalks were purchased from a local market at Kuala Nerus, Terengganu, Malaysia. The fresh lemongrass stalks with the moisture content of
$80.0 \pm 5.0 \%$ (w.b) were cut into $16 \mathrm{~cm}$ length and chopped into small pieces for preparation of freeze-dried lemongrass powder. Rice starch and standard of citral compound (assigned as $99.8 \%$ purity) was purchased from Sigma-Aldrich Co. The analytical grade chemical solvents of dichloromethane and n-hexane were supplied by Merck $\mathrm{KGaH}$ (Darmstadt, Germany) and $\mathrm{HmbG}$ Chemical (Hamburg, Germany) respectively.

\subsection{Preparation of gelatinised rice starch powder}

The gelatinised rice starch was prepared using the modified method following Jouquand et al. (2006) and $\mathrm{Xi}$ et al. (2015). About $6.00 \pm 0.05 \mathrm{~g}$ of rice starch was homogenised with $200 \mathrm{~mL}$ of distilled water, heated up to $80.0 \pm 3.0^{\circ} \mathrm{C}$ and remained for 20 mins along with cooling down to $30^{\circ} \mathrm{C}$. Then, it was frozen at $-80.0 \pm 2.0^{\circ} \mathrm{C}$ prior to freeze-drying at $-50.0 \pm 2.0^{\circ} \mathrm{C}$ for 48 hrs. The heating plate of the freeze dryer was automated to $20.0 \pm 2.0^{\circ} \mathrm{C}$ on vacuum degree at $0.203 \mathrm{KPa}$. It was then ground into a powder form using a $0.25 \mathrm{~mm}$ microfine grinder (IKA ${ }^{\circledR}$ Werke Staufen - MF 10.21, Germany). The dispersed powder was fixed into a size of $250 \mu \mathrm{m}$ using a sieve shaker (Retsch Model AS 200 digit, Germany) by stacking and vibrating at the amplitude of 60 for 20 mins. Then, the powdered samples were collected and kept at $4.0 \pm 2.0^{\circ} \mathrm{C}$ in a ziplock polyethylene bag for further analysis.

\subsection{Preparation of the inclusion complex of rice starch- citral compound powder}

The preparation method of the inclusion complex of rice starch-citral compound was conducted similar to the preparation of gelatinised rice starch powder in Section 2.1 by following the method of Jouquand et al. (2006) and $\mathrm{Xi}$ et al. (2015) with some modifications. After gelatinised rice starch remained constant for 5 mins at a temperature of $80.0 \pm 3.0^{\circ} \mathrm{C}, 25.00 \pm 0.05 \mathrm{~mL}$ of $25 \mathrm{ppm}$ standard citral compound was added slowly while being homogenised and maintained at $80.0 \pm 3.0^{\circ} \mathrm{C}$ for another $15 \mathrm{mins}$ at $200 \mathrm{rpm}$. Then, the cooled dispersion was collected with the aqueous layer and frozen at $-80.0 \pm 2.0^{\circ} \mathrm{C}$ prior to the freeze-drying process at $-50.0 \pm 2.0^{\circ} \mathrm{C}$ for $48 \mathrm{~h}$. Then, the powdered samples were collected and kept at $4.0 \pm 2.0^{\circ} \mathrm{C}$ in a zip-lock polyethylene bag for further analysis.

\subsection{Preparation of lemongrass extract}

About $300.0 \pm 0.5 \mathrm{~g}$ of chopped lemongrass stalk was frozen in the freezer (MDF-U55V-PE, Panasonic, Japan) for $24 \mathrm{hrs}$ at $-80 \pm 2.0^{\circ} \mathrm{C}$ prior to freeze-drying at $-50.0 \pm 2.0^{\circ} \mathrm{C}$, following Ding et al. (2012). The heating plate of the freeze dryer was automated to $20.0 \pm 3.0^{\circ} \mathrm{C}$ on vacuum degree at $0.203 \mathrm{kPa}$. After the drying process 
ended, the dried lemongrass was ground into a powder form for $30 \mathrm{~s}$ with a microfine grinder (IKA ${ }^{\circledR}$ Werke Staufen - MF 10.21, Germany) prior to the hydrodistillation extraction of the lemongrass extract. In this study, the freeze-dried of lemongrass powder was chosen as our previous research found that it obtained higher citral concentration when compared to fresh lemongrass stalk and other lemongrass dried powders (Hashim et al., 2019).

The hydrodistillation method was modified from the study done by Tajidin et al. (2012) in which about $10.00 \pm 0.50 \mathrm{~g}$ of freeze-dried lemongrass powder was mixed with $250 \mathrm{~mL}$ of distilled water upon extraction for $2 \mathrm{hrs}$ at $100.0 \pm 3.0^{\circ} \mathrm{C}$ to obtain a lemongrass extract from the Clevenger-type apparatus. The lemongrass extract was separated from the distilled water by liquid-liquid separation with the addition of $100.0 \pm 0.05 \mathrm{~mL}$ of dichloromethane. The organic solvent was then removed with a rotary evaporator at $40^{\circ} \mathrm{C}$ for $10 \mathrm{~min}$ to make a yellowish lemongrass extract appeared at the bottom of the round-bottom flask. The extract was transferred into a $2 \mathrm{~mL}$ vial for storage at $4^{\circ} \mathrm{C}$ before being encapsulated with rice starch. The yield of lemongrass extract was calculated using the following equation:

$$
\text { Yield of lemongrass extract }(\%)=\frac{\text { Lemongrass extract }(\mathrm{g})}{\text { Freeze-dried lemongrass powder (g) }} \times 100
$$

\subsection{Preparation of inclusion complex of rice starch- lemongrass extract}

The preparation method of the inclusion complex of rice starch-lemongrass extract is similar to the preparation of gelatinised rice starch in Section 2.1 according to the method of Jouquand et al. (2006) and Xi et al. (2015) with some modifications. After remaining the gelatinised rice starch for $5 \mathrm{~min}$ at a temperature of $80.0 \pm 3.0^{\circ} \mathrm{C}$, a $1.00 \pm 0.05 \mathrm{~mL}$ of lemongrass extract was added slowly while being homogenised and maintained at $80.0 \pm 3.0^{\circ} \mathrm{C}$ for another $15 \mathrm{~min}$ at $200 \mathrm{rpm}$. Then, the cooled dispersion was collected with the aqueous layer frozen at $-80.0 \pm 2.0^{\circ} \mathrm{C}$ prior to the freeze-drying process at $-50.0 \pm 2.0^{\circ} \mathrm{C}$ for $48 \mathrm{~h}$. Then, the powdered samples were collected and kept at $4.0 \pm 2.0^{\circ} \mathrm{C}$ in a zip-lock polyethylene bag for further analysis.

\subsection{Determination of morphological structure}

The morphological structures of the rice starch, gelatinised rice starch, inclusion complex of rice starchcitral compound, and inclusion complex of rice starchlemongrass powder were observed using Scanning Electron Microscopy (SEM) (JEOL, JSM - 6360 LA, Japan) following Tonon et al. (2008). The sample powder was attached to a double-sided adhesive tape mounted on the SEM stubs. It was coated with $3.5 \mathrm{~mA}$ gold under a vacuum condition using an auto fine coater (JEOL, JFC - 1600, Japan). Then, it was examined and operated at an accelerating voltage of $5 \mathrm{Kv}$ under magnification of $300 \times$.

\subsection{Determination of crystallinity structure}

X-ray diffraction (XRD) using Siemens D - 500 Diffractometer was used to determine the XRD pattern and crystallinity degree of the rice starch, gelatinised rice starch, inclusion complex of rice starch-citral compound, and inclusion complex of rice starch-lemongrass extract according to Wang et al. (2002) method. Each of the samples was placed and slightly pressed on an aluminium holder using a glass slide. It was operated at a wavelength of $0.154 \mathrm{~nm}$ and the output energy was set at $15 \mathrm{~mA}$ and $30 \mathrm{kV}$. Diffractogram was taken at $5^{\circ}-50^{\circ}$ $(2 \theta)$ at a steep $0.1^{\circ}$ angle and a scan rate of $2 \mathrm{~s}$ per steep. The XRD patterns were plotted to compare all the samples and the degree of crystallinity was determined using the following equation:

Crystallinity Degree $(\%)=\frac{\text { Area of the crystallised region }}{\text { Area of the crystallised region }+ \text { Area of the amorphous region }} \times 100$

\subsection{Determination of citral concentration}

\subsubsection{Extraction of citral compound}

The concentration of the citral compound on the inclusion complex of rice starch-citral compound and inclusion complex of rice starch-lemongrass extract was determined by Headspace-Solid Phase Microextraction (HS-SPME) following Hashim et al. (2019) with minor modifications. A $20 \mathrm{~mL}$ of $1000 \mathrm{ppm}$ stock solution of standard citral compound (assigned as $99.8 \%$ purity) was subjected to be prepared by diluting with distilled water for HS-SPME procedure with a series of concentrations of $25,50,75,100$ and $125 \mathrm{ppm}$.

A weight of $1.00 \pm 0.05 \mathrm{~g}$ of the inclusion-complex powder was added to the $45 \mathrm{~mL}$ of headspace vial. A heating block was used to equilibrate the temperature surrounding the vial. The citral compound extraction was conducted at $60^{\circ} \mathrm{C}$ for 30 mins along with SPME fibre coating composed of carboxen/polydimethylsiloxane (CAR/PDMS). The SPME CAR/PDMS coating was selected due to the less polar with high extraction efficiency and sensitivity in extracting hydrocarbon and monoterpenes compound (Caldeira et al., 2007). The CAR/PDMS fibre was immediately inserted into the injection port of the gas chromatography (GC 2010 Shimadzu, Japan) for 5 mins at $250^{\circ} \mathrm{C}$. The SPME fibre was then conditioned for the first usage for an hour at $350^{\circ} \mathrm{C}$ and reconditioned between analyses to prevent carryover. A blank test was conducted by desorbing the fibre for a second time to check the possibility of a carryover. 
The citral compound in lemongrass extract was identified and quantified by following Yahya et al. (2010) with minor modifications. A $1.00 \pm 0.05 \mathrm{~mL}$ of lemongrass extract was added with $10.00 \pm 0.05 \mathrm{~mL}$ of $n$ hexane into a $45 \mathrm{~mL}$ headspace vial before injected into the GC for analysis with splitless mode.

\subsubsection{Identification and quantification of citral compound}

Gas Chromatography-Flame Ionization Detector (GC-FID) was used to identify and quantify the citral compound of samples with GC 2010 (Shimadzu, Japan). The programme temperature setting was started at $60^{\circ} \mathrm{C}$ then increased by $4^{\circ} \mathrm{C} / \mathrm{min}$ to $150^{\circ} \mathrm{C}$, followed increased to $250^{\circ} \mathrm{C}$ at $20^{\circ} \mathrm{C} / \mathrm{min}$ and maintained at equilibrium for $5 \mathrm{~min}$. A RTX-5 capillary column $(30 \mathrm{~m} \times 0.25 \mathrm{~mm}$ internal diameter, $0.25 \mu \mathrm{m}$ film thickness) was used in this analysis. The chromatographic conditions were as follows: helium was used as a carrier gas. The flow of helium, hydrogen and air were set at $30.0 \mathrm{~mL} / \mathrm{min}, 40.0$ $\mathrm{mL} / \mathrm{min}$ and $400 \mathrm{~mL} / \mathrm{min}$, respectively; the temperature of the injector and detector was set at $250^{\circ} \mathrm{C}$ with the pressure of $100 \mathrm{kPa}$.

The two isomers of citral compound; neral and geranial were identified by comparing their retention times to the authentic standards. The concentration of citral compound was expressed as the sum of concentration of neral and geranial obtained from separated standard curve (peak area vs concentration).

\subsubsection{Entrapment efficiency of the citral compound}

The efficiency of citral entrapment was calculated using the equation from Zhang, Zhou, Cao et al. (2015): Entrapment Efficiency of Citral Compound $(\%)=\frac{\text { Citral concentration from rice starch inclusion complex }(\mathrm{ppm})}{\text { Initial }} \times 100$

The initial citral concentration of standard citral compound and lemongrass extract was $25.00 \pm 0.53$ ppm.

\subsection{Determination of thermal properties}

The thermal properties of the rice starch gelatinised rice starch, inclusion complex of rice starch-citral compound, and inclusion complex of rice starchlemongrass extract were determined using differential scanning calorimetry (DSC Q2000, TA Instruments, USA) with some modifications on the method of Simi and Abraham (2008). The DSC was calibrated for heat flow and temperature using standard indium. About $3.00 \pm 0.50 \mathrm{mg}$ of the sample powder was added with distilled water with the ratio of 1:4 $(\mathrm{w} / \mathrm{w})$ and sealed in an aluminium pan with a similar empty pan used as a reference. The sealed sample was stood for an hour while being agitated at $100 \mathrm{rpm}$. Scanning was carried out at $10^{\circ} \mathrm{C} / \mathrm{min}$ from 30 to $150^{\circ} \mathrm{C}$. Heating and cooling were carried out in a nitrogen gas atmosphere. Scanning of the samples was measured the temperature value of onset $\left(T_{o}\right)$, peak $\left(T_{p}\right)$, conclusion $\left(T_{c}\right)$, phase transition temperature range $\left(T_{r}\right)$, and enthalpy of gelatinisation $\left(\Delta \mathrm{H}_{\mathrm{gel}}\right)$ from the thermographs of the samples.

\subsection{Statistical analysis}

Data of the samples were analysed using MINITAB 14 software (MINITAB Inc., PA, USA). The one-way analysis of variance (One-way ANOVA) was used to determine the significant differences between the mean values of the samples followed by Fisher's Least Significant Difference (LSD) test at $\mathrm{p}<0.05$ for crystallinity degree and thermal properties among the samples. The independent $t$-test analysis was performed to compare the mean values between the citral retention from the inclusion complex of rice starch-citral compound and inclusion complex of rice starchlemongrass extract.

\section{Results and discussion}

\subsection{Morphological structure}

Figure 1 shows the morphological structure of the rice starch, gelatinised rice starch, inclusion complex of rice starch-citral compound, and inclusion complex of rice starch-lemongrass extract under SEM with a magnification of $300 \times$. The micrograph of rice starch granules exhibited a smooth polyhedral structure with a laminated appearance (Figure 1a) which is similar to the observation of Singh et al. (2006), Wani et al. (2012), and Chrungoo and Devi (2015). Figure 1b shows the prominent irregular structure with hole-like structure of the gelatinised rice starch. A small intercept on the large hole-like microstructure was observed which connected the edges as previously reported by Jung et al. (2017) on the structure of gelatinised rice grain. It indicates that the central region of the native starch was disrupted and became very loose with more water-uptake at a high heating temperature (Liu and Zhao, 1990).

The inclusion complex of rice starch-citral compound (Figure 1c) exhibited a similar observation to the inclusion complex of rice starch-lemongrass extract (Figure 1d) with irregular agglomerate-like structure with the presence of crumble on the laminated surface. This is due to the self-agglomeration of the rice starch with the volatile compound of the lemongrass extract during the inclusion complex formation as previously stated by Seo et al. (2010). The significant attributes shown by the microstructure of the rice starchlemongrass extract inclusion complex indicate the successful formation of the inclusion complex as 
reported by Zhang, Zhou, Cao et al. (2015) and Zhang et al. (2016).
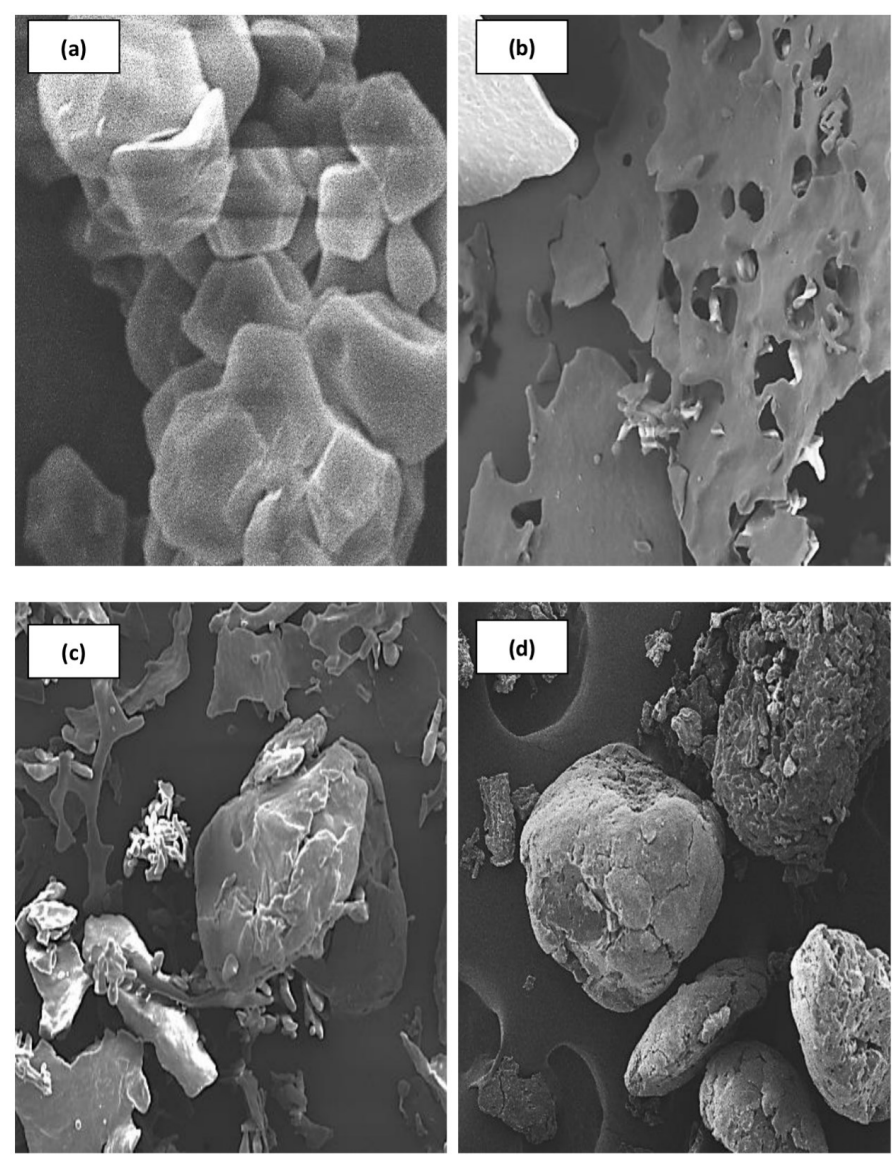

Figure 1. SEM microgram of a) rice starch, b) gelatinised rice starch, c) inclusion complex of rice starch-citral compound and d) inclusion complex of rice starchlemongrass extract at 300x magnification.

\subsection{Crystallinity structure}

Figure 2 shows the X-ray diffraction (XRD) patterns of the rice starch, gelatinised rice starch, inclusion complex of rice starch-citral compound, and inclusion complex of rice starch-lemongrass extract. The XRD pattern of the native rice starch (Figure 2a) shows a typical A-type pattern with strong diffraction peaks at $15^{\circ}, 17^{\circ}, 18^{\circ}$, and $23^{\circ}$ which are usually shown by cereal starch as reported in previous studies (Aguirre et al., 2011; You et al., 2015). Afterwards, the gelatinisation process was significantly attributed to the disappearance of the original peak and XRD pattern of the native starch (Aguirre et al., 2011). However, the V-type pattern was attributed to the appearance of a weak peak existing at $20^{\circ}$ (Ribotta et al., 2004) on the XRD pattern of gelatinised rice starch (Figure 2b) as reported by Khanh (2015). Both of the XRD patterns on the inclusion complex of rice starch-citral compound (Figure 2c) and inclusion complex of rice starch-lemongrass extract (Figure 2d) show V-type patterns similar to the gelatinised rice starch. The rice starch granules experienced mechanical damage during gelatinisation caused by the loss of its double helix structure and crystalline order (Eliasson and Wahlgren, 2004). The changes are associated with the chemical interaction of rice starch molecules with the citral compound to form an inclusion complex. The distinct change of diffraction patterns indicates a new solid crystallite was formed (Zhang, Li, Yu et al., 2015) due to the adjustment in the molecular structures (Abarca et al., 2016). The inclusion complex can be validated based on the merging of diffraction patterns, formation of new peaks, and disappearance of original peaks (Sinha et al., 2005).

(d)

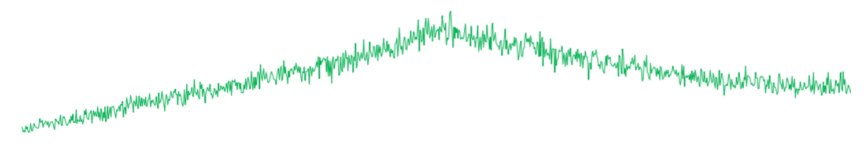

(c)

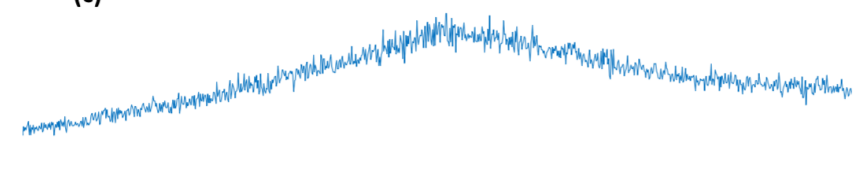

(b)

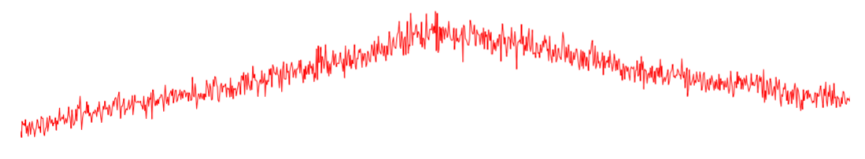

(a)

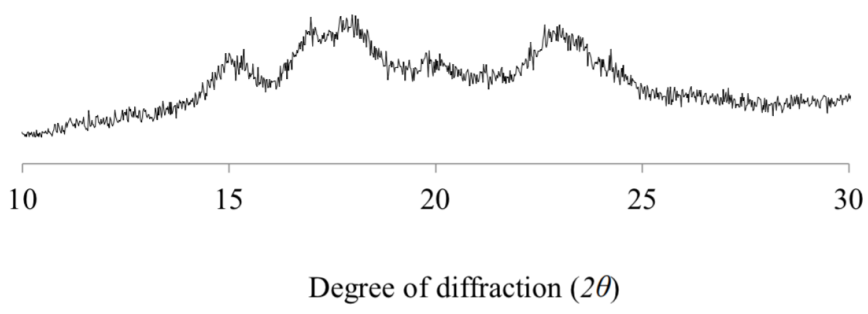

Figure 2. The X-ray diffraction (XRD) patterns of a) rice starch, b) gelatinised rice starch, c) inclusion complex of rice starch-citral compound and d) inclusion complex of rice starch-lemongrass extract.

Table 1 shows the crystallinity degree was significantly different $(p<0.05)$ for all of the rice starch, gelatinised rice starch, inclusion complex of rice starchcitral compound, and inclusion complex of rice starchlemongrass extract with a range of $2.75-11.81 \%$. As can be seen, the inclusion complex of the rice starch-citral compound showed the highest crystallinity degree $(11.81 \pm 0.78 \%)$ while the gelatinised rice starch showed the lowest crystallinity degree $(2.75 \pm 0.33 \%)$. The unexpected low crystallinity degree of the rice starch as reported by Yu et al. (2012) was due to the differences in rice cultivars, starch structure and distribution of amylose, and short and long side-chain amylopectin in 
the starch granules (Singh et al., 2007; Yu et al., 2012). Rice starch granules are mainly composed of amorphous fractions rather than crystalline fractions as the rice starch components are presented as a semi-crystalline structure (Wani et al., 2012) with a proportion of $30 \%$ crystalline and 70\% amorphous region (Donald, 2004). Meanwhile, the low crystallinity degree of the gelatinised rice starch is associated with a predominantly amorphous composition (Donald, 2004). Previous studies reported that gelatinised starch has no crystallites (Amagliani et al., 2016). It can be explained that the rice starch granules swelled and the crystalline organisation broke down into an amorphous region (Aguirre et al., 2011) while the double helix of the starch structural chains (Hu et al., 2014) and molecular orders of amylose and amylopectin (Biliaderis and Zawistowiski, 1990) were disrupted in the starch crystallites.

Table 1. Crystallinity degree $(n=3)$ of rice starch, gelatinised rice starch, inclusion complex of rice starch-citral compound and inclusion complex of rice starch-lemongrass extract powder

\begin{tabular}{lc}
\hline \multicolumn{1}{c}{ Powder } & $\begin{array}{c}\text { Crystallinity degree } \\
(\%)\end{array}$ \\
\hline Rice starch & $11.67 \pm 1.63^{\mathrm{a}}$ \\
Gelatinized rice starch & $2.75 \pm 0.33^{\mathrm{c}}$ \\
Inclusion complex of rice starch-citral & $11.81 \pm 0.78^{\mathrm{a}}$ \\
compound & $8.23 \pm 0.47^{\mathrm{b}}$ \\
\hline $\begin{array}{l}\text { Inclusion complex of rice starch- } \\
\text { lemongrass extract }\end{array}$ & \\
\hline
\end{tabular}

Mean with the different superscript letter in the same column is significantly different at $p<0.05$

The presence of standard citral compound caused a minor effect on the starch recrystallisation. The amylose chains of rice starch were recrystallised with amylopectin chains and in turn, chemically formed an inclusion complex of rice starch-citral compound soon after gelatinisation while being cooled down at the room temperature as reported by $\mathrm{Yu}$ et al. (2018) with a high rate at the first hours of cooling (Ribotta et al., 2004; Wang et al., 2015). In addition, the amorphous amylose fraction was organised into a crystalline fraction (Vandeputte et al., 2003; Wani et al., 2012) while the amylopectin fraction was directly recrystallised (Ribotta et al., 2003). On the contrary, the presence of lemongrass extract inhibited the rice starch recrystallisation by disturbing the reassociation between amylose and amylopectin chains during the cooling stage that the hydroxyl groups of guest molecules of lemongrass extract were chemically forming hydrogen bonds with the starch molecules as previously reported by $\mathrm{Fu}$ et al. (2014). The guest molecules of lemongrass extract acted as a physical barrier to prevent recrystallisation between amylose and amylopectin (Li et al., 2017). Nevertheless, the retardant effect of the starch recrystallisation was caused by both amylose and amylopectin interacting with the composition of lemongrass extract especially with the citral compound to form the inclusion complex of rice starch-lemongrass extract. For this reason, the retardant effect has the advantage of forming new starch -guest molecule helical complexes during the complex process (Gunaratne and Corke, 2007).

\subsection{Citral retention}

\subsubsection{Retention concentration of citral compound}

Table 2 shows the retention concentration of citral compound on the inclusion complex of rice starch-citral compound and inclusion complex of rice starchlemongrass extract. The retention concentration of citral compound showed a significant difference $(p<0.05)$ between both type of inclusion complexes as determined by $\mathrm{HS}-\mathrm{SPME}$ at $60^{\circ} \mathrm{C}$ for $30 \mathrm{mins}$ with the retention concentration of inclusion complex of rice starch-citral compound was $4.71 \pm 0.16 \mathrm{ppm}$ and inclusion complex of rice starch-lemongrass extract was $7.33 \pm 0.78 \mathrm{ppm}$. It explains that the citral compound (MW=152.23 $\mathrm{g} \mathrm{mol}^{-1}$ ) is easily diffuse out from the rice starch inclusion complex where previous studies reported that low molecular weight (Shahhoseini et al., 2013) compounds are easy to release from a solid sample. At the same time, this finding shows that rice starch is substantially able to act as a physical barrier in order to retain and lower the diffusion of citral compound out into the headspace. Aroma retention is strengthening with the chemical bonding between aroma molecules and starch structural chains (Kant et al., 2004) which justified the decreased in the mass transfer of aroma compounds (Lafarge et al., 2008). The non-polar aroma compounds are favoured by owing a greater degree of sorption in created structural bonding on the amylose structural chains as similarly reported by Samavati et al. (2012) on ethyl acetate retention in xanthan gum matrices. Citral compound is also formed weak inclusion complex with the side branches of amylopectin chains (Langourieux and Crouzet, 1995; Arvisenet et al., 2002) then forming an unstable interaction (Hansson et al., 2003) that contributed to the easy release of the citral compound during HS-SPME procedure.

It is interesting to note that thermal transformation might occur to other volatile composition of lemongrass extract into citral isomers of neral and geranial during inclusion complex formation. Previous studies reported that the verbenol have the potential to transform into citral isomers by opening their 4- and 6- membered rings under thermal condition (Maksimchuk et al., 2004). Baritaux et al. (1992) stated that linalyl acetate hydrolysed and transformed into linalool. Linalool is easily isomerized into geraniol and nerol and oxidizes to form neral and geranial (Misharina et al., 2003). This 
reaction increased the geranial and neral composition and at the same time, decreased the compounds with a similar chemical structure as citral isomers. Aoge et al. (1996) summarized the chemical reaction as geranyl acetate $\rightarrow$ geraniol $\rightarrow$ geranial $\rightarrow$ neral. This finding was in contrast with inclusion complex of rice starch-citral compound that thermal degradation and hydrodegradation of the citral compound occurred during the inclusion complex formation. The preparation temperature of inclusion complex gave significant impact to the formation of new compounds on the oil composition under oxidation reaction (Rasheed et al., 2016). A previous study reported that isomers of citral compound are degraded through oxidation into isomeric $m$ - and $p$-cymene (Misharina et al., 2003).

From that steric hindrance effect is formed from the inclusion complex formation by the host molecules of rice starch to give protection against the evaporation of aroma compounds (Wang et al., 2011) resulting in a lower concentration aroma concentration in the headspace (Hansson et al., 2003). It is a consequence of the adsorption, complexation by specific binding interactions between polysaccharide chains and aroma compounds (Secouard et al., 2003).

Table 2. Retention concentration and entrapment efficiency of citral compound from the inclusion complex of rice starchcitral compound and inclusion complex of rice starchlemongrass extract.

\begin{tabular}{lcc}
\hline Inclusion complex & $\begin{array}{c}\text { Retention } \\
\text { concentration }(\mathrm{ppm})\end{array}$ & $\begin{array}{c}\text { Entrapment } \\
\text { efficiency (\%) }\end{array}$ \\
\hline $\begin{array}{l}\text { Rice starch-citral } \\
\text { compound }\end{array}$ & $4.71 \pm 0.16^{\mathrm{b}}$ & $18.85 \pm 0.66^{\mathrm{b}}$ \\
$\begin{array}{l}\text { Rice starch- } \\
\text { lemongrass extract }\end{array}$ & $7.33 \pm 0.78^{\mathrm{a}}$ & $29.34 \pm 3.13^{\mathrm{a}}$ \\
\hline
\end{tabular}

Mean with the different superscript letter in the same column is significantly different at $\mathrm{p}<0.05$

\subsubsection{Entrapment efficiency of citral compound}

Table 2 shows the entrapment efficiency of the citral compound was significantly different $(p<0.05)$ between the inclusion complex of rice starch-citral compound and the inclusion complex of rice starch-lemongrass extract. The entrapment efficiencies of the citral compound were $18.85-29.34 \mathrm{ppm}$ where the inclusion complex of rice starch-lemongrass extract exhibited a greater entrapment efficiency of the citral compound. It is in a good agreement with Hill et al. (2013) and Tao et al. (2014) due to the effect of the aroma composition of lemongrass extract competing with other compounds as compared to the pure compound of citral. Rakmai et al. (2017) reported that carvacrol has to compete with other essential components of yarrow essential oilhydroxypropyl- $\beta$-cyclodextrin encapsulation. Despite that, it shows that rice starch was able to entrap the citral compound of lemongrass extract in the rice starch inclusion complex even though the aroma compound experienced high competition from other compositions of the lemongrass extract. This phenomenon is beneficial as stated by Arvisenet et al. (2002) regarding the cooperative effect where the first molecules are favoured in the formation of a second molecule complex.

\subsection{Thermal properties}

Table 3 shows the thermal transition temperatures (onset, $T_{o}$; peak, $T_{p}$; conclusion, $T_{c}$ ) were significantly different $(p<0.05)$ between the native rice starch, gelatinised rice starch, inclusion complex of rice starchcitral compound, and inclusion complex of rice starchlemongrass extract. Thermal transition temperatures appeared in the range of $T_{o}\left(64.52-138.83^{\circ} \mathrm{C}\right), T_{p}(70.56-$ $\left.138.95^{\circ} \mathrm{C}\right)$, and $T_{c}\left(79.34-142.93^{\circ} \mathrm{C}\right)$. It can be seen that the rice starch granules started to gelatinise at $64.52^{\circ} \mathrm{C}$ to $79.34^{\circ} \mathrm{C}$ which agrees to the endotherm range of 60.0 $85.0^{\circ} \mathrm{C}$ as previously stated by Singh et al. (2006) and Simi and Abraham (2008). The starch granule structurally swelled from absorbing water, causing a breakdown on the birefringence of granules as explained by Liu et al. (2002), Singh et al. (2003) and Li et al. (2004). When the rice starch gelatinised at $80^{\circ} \mathrm{C}$, the

Table 3. Thermal properties of rice starch, gelatinised rice starch, inclusion complex of rice starch-citral compound and inclusion complex of rice starch-lemongrass extract.

\begin{tabular}{cccccc}
\hline \multirow{2}{*}{ Sample } & \multicolumn{4}{c}{ Temperature $\left({ }^{\circ} \mathrm{C}\right)$} & \multirow{2}{*}{$\Delta \mathrm{H}_{\text {gel }}(\mathrm{J} / \mathrm{g})$} \\
\cline { 2 - 5 } & $T_{o}$ & $T_{p}$ & $T_{c}$ & $T_{c}-T_{o} / T_{r}$ & \\
\hline $\mathrm{A}$ & $64.52 \pm 0.23^{\mathrm{b}}$ & $70.58 \pm 1.11^{\mathrm{b}}$ & $79.34 \pm 0.80^{\mathrm{b}}$ & $14.82 \pm 1.03^{\mathrm{a}}$ & $0.80 \pm 0.31^{\mathrm{ab}}$ \\
$\mathrm{B}$ & $136.84 \pm 2.00^{\mathrm{a}}$ & $137.19 \pm 1.57^{\mathrm{a}}$ & $141.32 \pm 0.30^{\mathrm{a}}$ & $2.23 \pm 0.86^{\mathrm{b}}$ & $1.85 \pm 0.32^{\mathrm{a}}$ \\
$\mathrm{C}$ & $138.66 \pm 0.45^{\mathrm{a}}$ & $138.88 \pm 0.40^{\mathrm{a}}$ & $141.98 \pm 0.40^{\mathrm{a}}$ & $3.33 \pm 0.83^{\mathrm{b}}$ & $0.44 \pm 0.05^{\mathrm{b}}$ \\
$\mathrm{D}$ & $138.83 \pm 0.28^{\mathrm{a}}$ & $138.95 \pm 0.27^{\mathrm{a}}$ & $142.93 \pm 1.51^{\mathrm{a}}$ & $4.10 \pm 1.23^{\mathrm{b}}$ & $1.61 \pm 0.70^{\mathrm{a}}$ \\
\hline
\end{tabular}

Mean with the different superscript letter in the same column is significantly different at $p<0.05$. Key: A) rice starch, B) gelatinised rice starch, C) inclusion complex of rice starch-citral compound and D) inclusion complex of rice starch-lemongrass extract. $T_{o}$ : onset temperature, $\mathrm{T}_{\mathrm{p}}$ : peak temperature, $T_{c}$ : conclusion temperature, $T_{r}$ : phase transition temperature, $\Delta \mathrm{H}_{\mathrm{gel}}:$ enthalpy of gelatinisation. 
original thermal transition temperatures disappeared, and a small endothermic peak appeared at a higher temperature of $137.19 \pm 1.57^{\circ} \mathrm{C}$. The small amount of lipid content in the rice starch granule was at $0.3-0.56 \%$ as mentioned by Mohan et al. (2005) and Gani et al. (2017) where it caused higher thermal transition temperatures as reported by Dupuis et al. (2014). Previous studies identified that the high temperature of the endothermic peak is related to the melting of amylose -lipid complexes (Singh et al., 2007). The lipid content consequently interacted with the starch components in establishing the amylose-lipid complex formation during the gelatinisation process at $80^{\circ} \mathrm{C}$ and Tester (1997) identified that the lipid molecules extent complexed with amylose chains, directly affecting the gelatinisation properties. Meanwhile, the inclusion complex of rice starch-citral compound and inclusion complex of rice starch-lemongrass extract showed an insignificant thermal transition temperature at $138^{\circ} \mathrm{C}$ as shown in Table 3. It is similar to the inclusion complexes of eugenol- $\beta$-cyclodextrin (Seo et al., 2010) and garlic oil- $\beta$ -cyclodextrin (Wang et al., 2011). The presence of the standard citral compound and lemongrass extract in the form of essential oil affected the gelatinisation process by increasing the transition temperatures of inclusion complex powder which has a similar effect as reported by Baker and Rayas (1998). To some extent, the standard citral compound and composition of lemongrass extract replaced the water molecules and substituted on the rice starch structure, creating a stable structure interaction that improved the thermal stability of both rice starch inclusion complexes, as stated by Yoshimura et al. (1996).

The phase transition temperature range $\left(T_{r}\right)$ of starch gelatinisation directly reflected the quality and heterogeneity of the granular crystalline structure (Tester and Debon, 2000; Simi and Abraham, 2008). The thermal properties of $T_{r}$ were significantly different $(p<0.05)$ between the native rice starch, gelatinised rice starch, inclusion complex of rice starch-citral compound, and inclusion complex of rice starch-lemongrass extract. The $T_{r}$ was in the range of $2.33-14.82^{\circ} \mathrm{C}$ with native rice starch obtained the highest $T_{r}$ at $14.82 \pm 1.03^{\circ} \mathrm{C}$ and gelatinised rice starch shows the lowest $T_{r}$ at $2.23 \pm 0.86^{\circ} \mathrm{C}$. The broad $T_{r}$ of the rice starch indicated that wider heating temperature needed during gelatinisation to dissociate the crystalline region of the rice starch granule, as according to Singh et al. (2003), the starch gelatinisation process is firstly favoured in the amorphous regions due to the weak hydrogen bonding followed by crystalline regions.

The $T_{r}$ of gelatinised rice starch was significantly lower at $2.23 \pm 0.86^{\circ} \mathrm{C}$ but it was determined at the temperatures of $136.84-141.32^{\circ} \mathrm{C}$, which represent the $T_{r}$ for amylose-lipid complexes. It explains that the order of crystallite fractions of the rice starch granules was disrupted and disintegrated during gelatinisation which is in line with Amagliani et al. (2016), as the gelatinisation turned the crystalline regions of starch into amorphous regions. The low $T_{r}$ of gelatinised rice starch indicates that new amylose chain interactions were formed with endogenous lipid molecules of the rice starch during gelatinisation (Le Bail et al., 1999). Low $T_{r}$ for both rice starch inclusion complexes indicate the inclusion complex formation is structured less ordered and weak crystalline inclusion complex as identified by Sasaki et al. (2000) and Singh et al. (2003).

The enthalpy of gelatinisation $\left(\Delta \mathrm{H}_{\text {gel }}\right)$ reflects the energy required in the cause of losing the double-helical molecular order and crystallinity (Singh et al., 2006). It was significantly different $(p<0.05)$ between the rice starch, gelatinised rice starch, inclusion complex of rice starch-citral compound, and inclusion complex of rice starch-lemongrass extract as shown in Table 3. The $\Delta \mathrm{H}_{\text {gel }}$ was in the range of $0.44-1.85 \mathrm{~J} / \mathrm{g}$ where surprisingly, the inclusion complex of rice starch-citral compound resulted in the lowest $\Delta \mathrm{H}_{\text {gel }}$ of $0.44 \pm 0.05 \mathrm{~J} / \mathrm{g}$ and unexpectedly, the gelatinised rice starch obtained the highest $\Delta \mathrm{H}_{\text {gel }}$ of $1.85 \pm 0.32 \mathrm{~J} / \mathrm{g}$. In this study, lower thermal energy required to disintegrate rice starch granules under excess water might denote by the presence of high amylose content in the starch granules as reported by Biliaderis et al. (1986) on the presence of amylose fraction which promoted the decreasing in $\Delta \mathrm{H}$ of waxy and normal rice starches. The gelatinised rice starch shows high in $\Delta \mathrm{H}_{\text {gel }}$ at $1.85 \pm 0.32 \mathrm{~J} / \mathrm{g}$ where Anugrahati et al. (2017) previously reported that a high enthalpy could be due to the presence of non-starch components such as lipid and protein because lipid fractions absorb more heat energy (Singh et al., 2000).

The inclusion complex of rice starch-citral compound obtained a low $\Delta \mathrm{H}_{\text {gel }}$ at $0.44 \pm 0.05 \mathrm{~J} / \mathrm{g}$ due to the lower thermal energy required to dissociate the new structured and unstable interaction between the citral compound and rice starch granule. This is due to the interaction between the hydrophilic character of the hydroxyl $(-\mathrm{OH})$ group of the guest molecules of citral and the side chains of starch molecules, binding to the amorphous region of starch granules to various degrees in lowering the heat transfer rates and decreasing the mobility of water in the system (Xiao et al., 2011). The enthalpy of the inclusion complex of rice starchlemongrass extract was significantly higher than that of the inclusion complex of rice starch-citral compound. The compositions of lemongrass extract compound were co-operating to interact with the starch that strengthened 
the chemical bonding instead of the citral compound forming a chemical interaction with the starch polychains. The guest molecules of citral replaced the water molecules from the host cavity of starch and formed an inclusion composite, strengthening the interaction in the thermal stability (Zhang et al., 2018).

\section{Conclusion}

This study demonstrated that the morphological structure of the inclusion complex of rice starchlemongrass extract exhibited the presence of large penetrated holes forming on the smooth laminated multiangular inclusion-complex powders. The V-type diffraction pattern of the inclusion complex of rice starch -lemongrass extract showed a diffraction peak at $20^{\circ}$ with the crystallinity degree of $8.23 \pm 0.47 \%$. The formation of the rice starch inclusion complex is highly retained and efficiently entrapped the citral compound of lemongrass extract. The citral compound of lemongrass extract was protected inside the rice starch cavity from degradation as shown by the DSC thermogram with increased endothermic temperatures of the inclusion complex of rice starch-lemongrass extract from 138.83 to $142.93^{\circ} \mathrm{C}$ with the enthalpy of gelatinisation of $1.61 \pm 0.70 \mathrm{~J} / \mathrm{g}$. The stability of the citral compound from lemongrass extract is improved and protected by complexing with the rice starch inclusion complex from any unwanted modifications. This inclusion complex technique is regarded as an important strategy in designing a novel model of citral compound of lemongrass for food flavouring application.

\section{Conflict of Interest}

The authors declare that there is no conflict of interest regarding the publication of this research paper.

\section{Acknowledgement}

The authors are grateful to Universiti Malaysia Terengganu (UMT) for the facilities and financial support from the Research Accumulation Collaborative Effort (RACE) with Vote: 56035 grant scheme to conduct the research project.

\section{References}

Abarca, R.L., Rodríguez, F.J., Guelda, A., Galotto, M.J. and Bruna, J.E. (2016). Characterization of betacyclodextrin inclusion complexes containing an essential oil component. Food Chemistry, 196, 968975. https://doi.org/10.1016/j.foodchem.2015.10.023

Aguirre, J.F., Osella, C.A., Carrara, C.R., Sánchez, H.D. and Buera, M.P. (2011). Effect of storage temperature on starch retrogradation of bread staling.
Starch/Stärke, 63(9), 587-593.

https:// doi.org/10.1002/star.201100023

Amagliani, L., O'Regan, J., Kelly, A.L. and O'Mahony, J.A. (2016). Chemistry, structure, functionality and applications of rice starch. Journal of Cereal Science, 70, 291-300. https://doi.org/10.1016/ j.jcs.2016.06.014

Anugrahati, N.A., Pranoto, Y., Marsono, Y. and Marseno, D.W. (2017). Physicochemical properties of rice flour and starch of two Indonesian rice varieties differing in amylose content. International Food Research Journal, 24(1), 108-113.

Arvisenet, G. and Cayot, N. (2001). Influence of aroma compounds on large deformation properties of starch -based systems during aging. Journal of Texture Studies, 32(3), 185-203. https://doi.org/10.1111/ j.1745-4603.2001.tb01043.x

Arvisenet, G., Voilley, A. and Cayot, N. (2002). Retention of aroma compounds in starch matrices: competitions between aroma compounds towards amylose and amylopectin. Journal of Agricultural and Food Chemistry, 50, 7345-7349. https:// doi.org/10.1021/jf020532u

Baker, L.A. and Rayas-Duarte, P. (1998). Retrogradation of amaranth starch at different storage temperatures and the effect of salt and sugars. Cereal Chemistry, 75(3), 308-314. https://doi.org/10.1094/ CCHEM.1998.75.3.308

Baritaux, O., Richard, H., Touche, J. and Dersbesy, M. (1992). Effects of drying and storage of herbs and spices on the essential oil. Part I. Basil, Ocimum basilicum L. Flavour and Fragrance Journal, 7(5), 267-271. https://doi.org/10.1002/ffj.2730070507

Biliaderis, C.G., Page, C.M., Maurice, T.J. and Juliano, B.O. (1986). Thermal characterization of rice starches: a polymeric approach to phase transitions granular starch. Journal of Agricultural and Food Chemistry, 34, 6-14. https://doi.org/10.1021/ jf00067a002

Biliaderis, C.G. and Zawistowiski, J. (1990). Viscoelastic behaviour of aging starch gels: effects of concentration, temperature and starch hydrolysate on network properties. Cereal Chemistry, 67(3), 240246.

Caldeira, M., Rodrigues, F., Perestrelo, R., Marques, J.C. and Câmara, J.S. (2007). Comparison of two extraction methods for evaluation of volatile constituent's patterns in commercial whiskeys: Elucidation of the main odour-active compounds. Talanta, 74(1), 78-90. https://doi.org/10.1016/ j.talanta.2007.05.029

Carlson, L.H.C., Machado, R.A.F., Spricigo, C.B., 
Pereira, L.K. and Bolzan, A. (2001). Extraction of lemongrass essential oil with dense carbon dioxide. Journal of Supercritical Fluids, 21(1), 33-39. https:// doi.org/10.1016/S0896-8446(01)00085-7

Chrungoo, N.K. and Devi, A.G. (2015). Morphological and rheological properties of starches separated from cultivars of rice (Oryza sativa L.) from North East India. American Journal of Plant Science, 6, 20192031. https://doi.org/10.4236/ajps.2015.612202

Cohen, R., Orlova, Y., Kovalev, M., Ungar, Y. and Shimoni, E. (2008). Structural and functional properties of amylose complexes with genistein. Journal of Agricultural and Food Chemistry, 56(11), 4212-4218. https://doi.org/10.1021/jf800255c

Conde-Petit, B., Escher, F. and Nuessli, J. (2006). Structural features of starch-flavour complexation in food model systems. Trends in Food Science and Technology, 17(5), 227-235. https://doi.org/10.1016/ j.tifs.2005.11.007

Ding, S.H., An, K.J., Zhao, C.P., Li, Y., Guo, Y.H. and Wang, Z.F. (2012). Effect of drying methods on the volatiles of Chinese ginger (Zingiber officinale Roscoe). Food and Bioproducts Processing, 90(3), 515-524. https://doi.org/10.1016/j.fbp.2011.10.003

Donald, A.M. (2004). Understanding starch structure and functionality. In Eliasson, A.C. (Ed). Starch in food. Structure, function and applications, p. 156184. Cambridge: Woodhead Publishing Limited. https://doi.org/10.1533/9781855739093.1.156

Dupuis, J.H., Liu, Q. and Yada, R.Y. (2014). Methodologies for increasing the resistant starch content of food starches: A review. Comprehensive Reviews in Food Science and Food Safety, 13(6), 1219-1234. https://doi.org/10.1111/15414337.12104

Eliasson, A.C. and Wahlgren. (2004). Starch-lipid interactions and their relevance in food products. In Eliasson, A.C. (Ed.). Starch in food: structure, function and application, p. 441-460. Cambridge: Woodhead Publishing. https:// doi.org/10.1533/9781855739093.3.441

Francisco, V., Figueirinha, A., Neves, B.M., GarcíaRodríguez, C., Lopes, M.C., Cruz, M.T. and Batista, M.T. (2011). Cymbopogon citratus as source of new and safe anti-inflammatory drugs: bio-guided assay using lipopolysaccharide-stimulated macrophages. Journal of Ethnopharmacology, 133(2), 818-827. https://doi.org/10.1016/j.jep.2010.11.018

Fu, Z., Chen, J., Luo, S.J., Liu, C.M. and Liu, W. (2014). Effect of food additives on starch retrogradation: A review. Starch/Stärke, 67(1-2), 69-78. https:// doi.org/10.1002/star.201300278
Gani, A., Ashwar, B.A., Akhter, G., Shah, A., Wani, I.A. and Masoodi, F.A. (2017). Physico-chemical, structural, pasting and thermal properties of starches of fourteen Himalayan rice cultivates. International Journal of Biological Macromolecules, 95, 11011107. https://doi.org/10.1016/j.ijbiomac.2016.10.100

Gharsallaoui, A. Roudaut, G., Chambin, O., Voilley, A. and Saurel, R. (2007). Applications of spray-drying in microencapsulation of food ingredients: an overview. Food Research International, 40(9), 1107 -1121. https://doi.org/10.1016/j.foodres.2007.07.004

Gunaratne, A. and Corke, H. (2007). Influence of unmodified and modified cycloheptaamylose $(\beta$ cyclodextrin) on transition parameters of amyloselipid complex and functional properties of starch. Carbohydrate Polymers, 68(2), 226-234. https:// doi.org/10.1016/j.carbpol.2006.12.017

Gupta, S., Khan, S., Muzafar, S., Kushwaha, M., Yadav, A.K. and Gupta, A.P. (2016). Encapsulation: entrapping essential oil/flavors/aromas in food. Nanotechnology in the Agri-Food Industry., p. 229268. New York: Academic Press. https:// doi.org/10.1016/B978-0-12-804307-3.00006-5

Hansson, A., Leufvén, A. and Van Ruth, S. (2003). Partition and release of 21 aroma compounds during storage of a pectin gel system. Journal of Agricultural and Food Chemistry, 51, 2000-2005. https://doi.org/10.1021/jf021096e

Hashim, M.A., Yahya, F. and Wan Mustapha, W.A. (2019). Effect of different drying methods on the morphological structure, colour profile and citral concentration of lemongrass (Cymbopogon citratus) powder. Asian Journal of Agricultural and Biology, 7(1), 93-102.

Hill, L. E., Gomes, C. and Taylor, T.M. (2013). Characterization of beta-cyclodextrin inclusion complexes containing essential oils (transcinnamaldehyde, eugenol, cinnamon bark, and clove bud extracts) for antimicrobial delivery applications. LWT-Food Science and Technology, 51(1), 86-93. https://doi.org/10.1016/j.1wt.2012.11.011

Hu, X.P., Xie, Y.Y., Jin, Z.Y., Xu, X.M. and Chen, H.Q. (2014). Effects of single-, dual-, and tripleretrogradation treatments on in vitro digestibility and structural characteristics of waxy wheat starch. Food Chemistry, 157, 373-379. https://doi.org/10.1016/ j.foodchem.2014.02.065

Itthisoponkul, T., Mitchell, J.R., Taylor, A.J. and Farhat, I.A. (2007). Inclusion complexes of tapioca starch with flavour compounds. Carbohydrate Polymers, 69(1), 106-115. https://doi.org/10.1016/ j.carbpol.2006.09.012 
Jouquand, C., Ducruet, V. and Le Bail, P. (2006). Formation of amylose complexes with C6-aroma compounds in starch dispersions and its impact on retention. Food Chemistry, 96(3), 461-470. https:// doi.org/10.1016/j.foodchem.2005.03.001

Jung, K.J., Lee, H., Lee, S.H. and Kim, J.C. (2017). Retrogradation of heat-gelatinised rice grain in sealed packaging: investigation of moisture relocation. Food Science and Technology, Campinas, 37(1), 97-102.

Kant, A., Linforth, R.S.T., Hort, J. and Taylor, A.J. (2004). Effect of $\beta$-cyclodextrin on aroma release and flavor perception. Journal of Agricultural and Food Chemistry, 52, 2028-2035. https:// doi.org/10.1021/jf0307088

Katsukawa, M., Nakata, R., Takizawa, Y., Hori, K., Takahashi, S. and Inoue, H. (2010). Citral, a component of lemongrass oil, activates PPAR $\alpha$ and $\gamma$ and suppressed COX -2 expressions. Biochimica et Biophysica Acta (BBA) - Molecular and Cell Biology and Lipids, 1801(11), 1214-1220. https:// doi.org/10.1016/j.bbalip.2010.07.004

Keatkrai, J., Lumdubwong, N., Chaiseri, S. and Jirapakkul, W. (2017). Characteristics of menthone encapsulated complex by mungbean, tapioca and rice starches. International Journal of Food Properties, 20(4), 810-820. https:// doi.org/10.1080/10942912.2016.1183129

Khanh, S.T. (2015). Recrystallization of starches by hydrothermal treatment: digestibility, structural and physicochemical properties. Journal of Food Science and Technology, 52(12), 7640-7654. https:// doi.org/10.1007/s13197-015-1945-6

Lafarge, C., Bard, M.H., Breuvart, A., Doublier, J.L. and Cayot, N. (2008). Influence of the structure of cornstarch dispersions on kinetics of aroma release. Journal of Food Science, 73(2), 104-109. https:// doi.org/10.1111/j.1750-3841.2007.00645.x

Langourieux, S. and Crouzet, J. (1995). Interactions between polysaccharides and aroma compounds. In Charalambous, G. (Ed.) Food Flavors: Generation, Analysis and Process Influence, p. 1173-1186. London, UK: Elsevier. https://doi.org/10.1016/S0167 -4501(06)80228-1

Le Bail, P., Bizot, H., Ollivon, M., Keller, G., Bourgaux, C. and Buléon, A. (1999). Monitoring the crystallization of amylose-lipid complexes during maize starch melting by synchrotron X-ray diffraction. Biopolymers, 50(1), 99-110. https:// doi.org/10.1002/(SICI)1097-0282(199907)

50:1<99::AID-BIP9>3.0.CO;2-A

Li, F.D., Li, T.L., Li, Z. and Tatsumi, L. (2004).
Determination of starch gelatinization by ohmic heating. Journal of Food Engineering, 62(2), 113120. https://doi.org/10.1016/S0260-8774(03)00199-7

Li, Q.Q., Wang, Y.S., Chen, H.H., Liu, S. and Li, M. (2017). Retardant effect of sodium alginate on the retrogradation properties of normal corn starch and anti-retrogradation mechanism. Food Hydrocolloids, 69, $1-9 . \quad$ https://doi.org/10.1016/ j.foodhyd.2017.01.016

Liu, J.M. and Zhao, S.L. (1990). Scanning electron microscope study on gelatinization of starch granules in excess water. Starch/Stärke, 42(3), 96-98. https:// doi.org/10.1002/star.19900420305

Liu, Q., Charlet, G., Yellec, S. and Arul, J. (2002). Phase transition in potato starch - water system I. Starch gelatinization at high moisture level. Food Research International, 35(4), 397-407. https:// doi.org/10.1016/S0963-9969(01)00134-X

Maksimchuk, N.V., Simakova, I.L. and Semikolenov, V.A. (2004). Kinetic study on isomerization of verbenol to isopiperitenol and citral. Reaction Kinetics, Mechanism and Catalysis, 82(1), 165-172. https://doi.org/10.1023/

B:REAC.0000028818.12903.f3

Misharina, T.A., Polshkov, A.N., Ruchkina, E.L. and Medvedeva, I.B. (2003). Changes in the composition of the essential oil of marjoram during storage. Applied Biochemistry and Microbiology, 39, 353358.

Mohamed Hanaa, A.R.M., Sallam, Y.I., El - Leithy, A.S. and Aly, S.E. (2012). Lemongrass (Cymbopogon citratus) essential oil as affected by drying method. Annals of Agricultural Science, 57(2), 113-116. https://doi.org/10.1016/j.aoas.2012.08.004

Mohan, B.H., Gopal, A., Malleshi, N.G. and Tharanathan, R.N. (2005). Characteristics of native and enzymatically hydrolyzed ragi (Eleusine coracana) and rice (Oryza sativa) starches. Carbohydrate Polymer, 59(1), 43-50. https:// doi.org/10.1016/j.carbpol.2004.08.022

Nakahara, K., Alzoreky, N.S., Yoshihashi, T., Nguyen, H.T.T. and Trakoontivakorn, G. (2003). Chemical composition and antifungal activity of essential oil from Cymbopogon nardus (citronella grass). Japan Agricultural Research Quarterly, 37(4), 249-252. https://doi.org/10.6090/jarq.37.249

Nazarro, F. Orlando, P., Fratianni, F. and Coppola, R. (2012). Microencapsulation in food science and biotechnology. Current Opinion in Biotechnology, 23(2), 182-186. https://doi.org/10.1016/ j.copbio.2011.10.001

Putseys, J.A., Lamberts, L. and Delcour, J.A. (2010). 
Amylose - inclusion complexes: Formation, identity and physicochemical properties. Journal of Cereal Science, 51(3), 238-247. https://doi.org/10.1016/ j.jcs.2010.01.011

Rakmai, J., Cheirsilp, B., Tarrado-Agrasar, A., SimalGándara, J. and Mejuto, J.C. (2017). Encapsulation of yarrow essential oil in hydroxypropyl- $\beta$ cyclodextrin: physicochemical characterization and evaluation of bio-efficacies. CyTA-Journal of Food, 15(3), 409-417. https:// doi.org/10.1080/19476337.2017.1286523

Rasheed, A.S.E, Abu-Bakr, A. A-G, Hassan El-S.K. and Gaffar, M, El-H. (2016). Evaporation of spearmint (Mentha spicata var. viridis L.) herb oil during one year of storage under semi-arid condition. Agricultural Research and Technology, 2(4), 110114. https://doi.org/10.19080/ ARTOAJ.2016.02.555594

Ribotta, P.D., Leon, A.E. and Añon, M.C. (2003). Effect of freezing and frozen storage on gelatinization and retrogradation of amylopectin in dough baked in a differential scanning calorimetry. Food Research International, 36(4), 357-363. https:// doi.org/10.1016/S0963-9969(02)00227-2

Ribotta, P.D., Cuffini, S., León, A.E. and Añón, M.C. (2004). The staling of bread: an X-ray diffraction study. European Food Research and Technology, 218(3), 219-223. https://doi.org/10.1007/s00217-003 $-0835-8$

Ruktanonchai, U. R., Srinuanchai, W., Saesoo, S., Sramala, I., Puttipipatkhachorn, S. and Soottitantawat, A. (2011). Encapsulation of citral isomers in extracted lemongrass oil with cyclodextrins: molecular modeling and physicochemical characterizations. Bioscience, Biotechnology and Biochemistry, 75(12), 2340-2345. https://doi.org/10.1271/bbb.110523

Samavati, V., Emam-Djomeh, Z., Mehdinia, M.A., Mohammadifar, M.A. and Omid, M. (2012). Effect of composition on release of aroma compounds. Iranian Journal of Chemistry and Chemical Engineering, 31(3), 85-96.

Sasaki, T., Yasui, T. and Matsuki, J. (2000). Effect of amylose content on gelatinization, retrogradation and pasting properties of starches from waxy and nonwaxy wheat and their F1 seeds. Cereal Chemistry, 77(1), 58-63. https://doi.org/10.1094/ CCHEM.2000.77.1.58

Schaneberg, B.T. and Khan, I.A. (2002). Comparison of extraction methods for marker compounds in the essential oil of lemongrass by GC. Journal of Agricultural and Food Chemistry, 50, 1345-1349. https://doi.org/10.1021/jf011078h
Secouard, S., Malhiac, C., Grisel, M. and Decroix, B. (2003). Release of limonene from polysaccharide matrices: Viscosity and synergy effect. Food Chemistry, 82(2), 227-234. https://doi.org/10.1016/ S0308-8146(02)00518-6

Seo, E.J., Min, S.G. and Choi, M.J. (2010). Release characteristics of freeze-dried eugenol encapsulated with $\beta$-cyclodextrin by molecular inclusion method. Journal of Microencapsulation, 27(6), 496-505. https://doi.org/10.3109/02652041003681398

Shah, G., Shri, R., Panchal, V., Sharma, N., Singh, B. and Mann, A.S. (2011). Scientific basis for the therapeutic use of Cymbopogon citratus Stapf (lemongrass). Journal of Advanced Pharmaceutical Technology and Research, 2(1), 3-8. https:// doi.org/10.4103/2231-4040.79796

Shahhoseini, R., Estaji, A., Hosseini, N., Ghorbanpour, M. and Omidbaigi, R. (2013). The effect of different drying methods on the content and chemical composition of essential oil of lemon verbena (Lippia citriodora). Journal of Essential Oil Bearing Plant, 16(4), 474-481. https:// doi.org/10.1080/0972060X.2013.813270

Simi, C.K. and Abraham, T.E. (2008). Physicochemical rheological and thermal properties of Njavara Rice (Oryza sativa) starch. Journal of Agricultural and Food Chemistry, 58, 12105-12113. https:// doi.org/10.1021/jf802572r

Singh, V., Okadome, H., Toyoshima, H., Isobe, S. and Ohtsubo, K. (2000). Thermal and physicochemical properties of rice grain, flour and starch. Journal of Agricultural and Food Chemistry, 48, 2639-2647. https://doi.org/10.1021/jf990374f

Singh, N., Singh, J., Kaur, L., Sodhi, N.S. and Gill, B.S. (2003). Morphological, thermal and rheological properties of starches from different botanical sources. Food Chemistry, 81(2), 219-231. https:// doi.org/10.1016/S0308-8146(02)00416-8

Singh, N., Kaur, L., Sandhu, K.S., Kaur, J. and Nishinari, K. (2006). Relationship between physicochemical, morphological, thermal, rheological properties of rice starches. Food Hydrocolloids, 20(4), 532-542. https://doi.org/10.1016/j.foodhyd.2005.05.003

Singh, N., Nakaura, Y., Inouchi, N. and Nishinari, K. (2007). Fine structure, thermal and viscoelastic properties of starches separated from indica rice cultivars. Starch/Stärke, 59(1), 10-20. https:// doi.org/10.1002/star.200600527

Sinha, V., Anitha, R., Ghosh, S., Nanda, A. and Kumria, R. (2005). Complexation of celecoxib with $\beta$ cyclodextrin: characterization of the interaction in solution and in solid state. Journal of 
Pharmaceutical Sciences, 94(3), 676-687. https:// doi.org/10.1002/jps.20287

Tajidin, N.E., Ahmad, S.H., Rosenani, A.B., Azimah, H. and Munirah, M. (2012). Chemical composition and citral content in lemongrass (Cymbopogon citratus) essential oil at three maturity stages. African Journal of Biotechnology, 11(11), 2685-2693. https:// doi.org/10.5897/AJB11.2939

Tao, F., Hill, L.E., Peng, Y. and Gomes, C.L. (2014). Synthesis and characterization of $\beta$-cyclodextrin inclusion complexes of thymol and thyme oil for antimicrobial delivery applications. LWT-Food Science and Technology, 59(1), 247-255. https:// doi.org/10.1016/j.lwt.2014.05.037

Tester, R.F. (1997). Starch: The polysaccharide fractions. In Frazier, P.J., Richmond, P. and Donald, A.M. (Eds.). Starch structure and functionality, p. 163-171. Cambridge, UK: The Royal Society of Chemistry.

Tester, R.F. and Debon, S.J.J. (2000). Annealing of starch - a review. International Journal of Biological Macromolecules, 27(1), 1-12. https:// doi.org/10.1016/S0141-8130(99)00121-X

Tonon, R.V., Brabet, C. and Hubinger, M.D. (2008). Influence of process conditions on the physicochemical properties of açai (Euterpeoleraceae Mart.) powder produced by spray drying. Journal of Food Engineering, 88(3), 411418. https://doi.org/10.1016/j.jfoodeng.2008.02.029

Van Ruth S.M. and King, C. (2003). Effect of starch and amylopectin concentrations on volatile flavour release from aqueous model food systems. Flavour and Fragrance Journal, 18(5), 407-416. https://doi.org/10.1002/ffj.1240

Vandeputte, G.E., Vermeylen, R., Geeroms, J. and Delcour, J.A. (2003). Rice starches. I. Structural aspects provide insight into crystallinity characteristics and gelatinization behaviour of granular starch. Journal of Cereal Science, 38(1), 43 -52. https://doi.org/10.1016/S0733-5210(02)00140-6

Vaughn, J., Wu, H., Efremovska, B., Olson, D.H., Mattai, J., Ortiz, C., Puchalski, A., Li, J. and Pan, L. (2009). Encapsulated recyclable porous materials: an effective moisture-triggered flavor release system. Chemical Communications, 49, 5724-5726. https:// doi.org/10.1039/c3cc41236a

Wang, L., Wang, Y.J. and Porter, R. (2002). Structures and physicochemical properties of six wild rice starches. Journal of Agricultural and Food Chemistry, 50, 2695-2699. https://doi.org/10.1021/ jf011379r

Wang, J., Cao, Y., Sun, B. and Wang, C. (2011).
Physicochemical and release characterization of garlic oil- $\beta$-cyclodextrin inclusion complexes. Food Chemistry, 127(4), 1680-1685. https:// doi.org/10.1016/j.foodchem.2011.02.036

Wang, X., Yuan, Y. and Yue, T. (2015). The application of starch-based ingredients in flavor encapsulation. Starch/Stärke, 67(3-4), 225-236. https:// doi.org/10.1002/star.201400163

Wang, S., Lii, C., Copeland, L., Niu, Q. and Wang, S. (2015). Starch retrogradation: a comprehensive review. Comprehensive Reviews in Food Science and Technology, 14(5), 568-585. https:// doi.org/10.1111/1541-4337.12143

Wani, A.A., Singh, P., Shah, M.A. Schweiggert - Weisz, U., Gul, K. and Wani, I.A. (2012). Rice starch diversity: Effects on structural, morphological, thermal and physicochemical properties - a review. Comprehensive Reviews in Food Science and Food Safety, 11(5), 417-436. https://doi.org/10.1111/ j.1541-4337.2012.00193.x

Weisheimer, V., Miron, D., Silva, C.B., Guterres, S.S. and Schapoval, E.E.S. (2010). Microparticles containing lemongrass volatile oil: preparation, characterization and thermal stability. Pharmazie, 65 (12), 885-890.

Wulff, G., Avgenaki, G. and Guzmann, M.S.P. (2005). Molecular encapsulation of flavours as helical inclusion complexes of amylose. Journal of Cereal Science, 41(3), 239-249. https://doi.org/10.1016/ j.jcs.2004.06.002

Xi, J., Qian, D., Duan, J., Liu, P. Zhu, Z., Guo, J., Zhang, Y. and Pan, Y. (2015). Preparation, characterization and pharmacokinetic study of Xiangfu Siwu decoction essential oil/ $\beta$-Cyclodextrin inclusion complex. Molecules, 20(6), 10705-10720. https:// doi.org/10.3390/molecules200610705

Xiao, H., Lin, Q., Liu, G.Q., Wu, Y., Tian, W., Wu, W. and $\mathrm{Fu}, \mathrm{X}$. (2011). Effect of green tea polyphenols on the gelatinization and retrogradation of rice starches with different amylose contents. Journal of Medicinal Plants Research, 5(17), 4298-4303.

Xiao, Z., Feng, N., Zhu, G. and Niu, Y. (2015). Preparation and application of citralmonochlorotriazine- $\beta$-cyclodextrin inclusion complex nanocapsule. The Journal of the Textile Institute, 107(1), 64-71. https:// doi.org/10.1080/00405000.2014.1000579

Yahya, F., Lu, T., Santos, R.C.D., Fryer, P.J. and Bakalis, S. (2010). Supercritical carbon dioxide and solvent extraction of 2-acetyl-pyrroline from Pandan leaf: The effect of pre-treatment. Journal of Supercritical Fluids, 55(1), 200-207. https:// 
doi.org/10.1016/j.supflu.2010.05.027

Yahya, F., Abdul Rahim, A.M. and Hashim, M.A. (2016). Effect of different ratios of Arabic gum and maltodextrin on the physical properties and aroma retention of encapsulated lemongrass (Cymbopogon citratus) powder, presented at the $13^{\text {th }}$ Universiti Terengganu International Annual Symposium on Sustainability Science and Managemnet (UMTAS 2016), p. 699-710. Kuala Terengganu, Terengganu, Malaysia: Universiti Malaysia Terengganu.

Yoshimura, M., Takaya, T. and Nishinari, K. (1996). Effects of konjac-glucomannan on the gelatinization and retrogradation of corn starch as determined by rheology and differential scanning calorimetry. Journal of Agricultural and Food Chemistry, 44, 2970-2976. https://doi.org/10.1021/jf960221h

You, S.Y., Oh, S.K., Kim, H.S. and Chung, H.J. (2015). Influence of molecular structure on physicochemical properties and digestibility of normal rice starches. International Journal of Biological Macromolecules, 77, 375-382. https://doi.org/10.1016/ j.ijbiomac.2015.02.054

Yu, S., Ma, Y., Menager, L. and Sun, D.W. (2012). Physicochemical properties of starch and flour from different rice cultivars. Food Bioprocess and Technology, 5, 626-637. https://doi.org/10.1007/ s11947-010-0330-8

Yu, Z., Wang, Y.S., Chen, H.H. and Li, Q.Q. (2018). Effect of sodium alginate on the gelatinization and retrogradation properties of two tuber starches. Cereal Chemistry, 95(3), 445-455. https:// doi.org/10.1002/cche.10046

Zhang, H. X., Tian, Y.Q., Bai, Y.X., Xu, X.M. and Jin, Z.Y. (2013). Structure and properties of maize starch processed with a combination of $\alpha$-amylase and pullulanase. International Journal of Biological Macromolecules, 52, 38-44. https://doi.org/10.1016/ j.ijbiomac.2012.09.030

Zhang, W., Li, X., Yu, T., Yuan, L., Rao, G., Li, D. and $\mathrm{Mu}, \quad$ C. (2015). Preparation, physicochemical characterization and release behaviour of the inclusion complex of trans-anethole and $\beta$ cyclodextrin. Food Research International, 74, 5562. https://doi.org/10.1016/j.foodres.2015.04.029

Zhang, Y., Zhou, Y., Cao, S., Li, S., Jin, S. and Shu, Z. (2015). Preparation, release and physicochemical characterisation of ethyl butyrate and hexanal inclusion complexes with $\beta$-and $\gamma$-cyclodextrin. Journal of Microencapsulation, 32(7), 711-718. https://doi.org/10.3109/02652048.2015.1073391

Zhang, J.Q., Jiang, K.M., Xie, X.G., Yi, J. and Jun, L. (2016). Water-soluble inclusion complexes of transpolydatin by cyclodextrin complexation;
Preparation, characterization and bioactivity evaluation. Journal of Molecular Liquids, 219, 592598. https://doi.org/10.1016/j.molliq.2016.03.054

Zhang, Y., Zhang, H., Wang, F. and Wang, L.X. (2018). Preparation and properties of ginger essential oil $\beta$ cyclodextrin/chitosan inclusion complexes. Coatings, 8(9), 305-317. https://doi.org/10.3390/ coatings 8090305 